\title{
Anterior Rectal Duplication Cyst: A Rare Case Report
}

\author{
Kishor Taori, P. P. Gour, Darshan Patwa*, Jawahar Rathod, Amit Disawal, \\ Anand Hatgaonkar, Ashwini Bakade, Akshat Kasat, Chandrakant Kamble
}

Department of Radiodiagnosis, Government Medical College, Nagpur, India

Email: ${ }^{\text {dpatwa66@gmail.com }}$

Received 31 March 2015; accepted 16 April 2015; published 20 April 2015

Copyright (C) 2015 by authors and OALib.

This work is licensed under the Creative Commons Attribution International License (CC BY). http://creativecommons.org/licenses/by/4.0/

(c) (i) Open Access

\begin{abstract}
Introduction: We present an unusual case of an anterior rectal duplication cyst in a 9-month-old male infant. This rare variant of rectal duplications is presented with acute urinary retention. The diagnosis is challenging and multiple differential diagnoses can be considered. Varied clinical presentations and imaging characteristic of this rare entity are discussed. The awareness of this variant leads to the early diagnosis and the curative resection.
\end{abstract}

Keywords

Anterior Rectal Duplication Cyst, Radiological Imaging, CT, MRI

Subject Areas: Radiology \& Medical Imaging

\section{Introduction}

Intestinal duplications are rare developmental anomalies that can occur anywhere along the gastrointestinal tract. Intestinal duplications were originally described in 1941, by Ladd and Gross, as having an attachment or adherence to some parts of the gastrointestinal tract, the presence of a smooth muscle wall and a mucosal lining with one or more cell types of the gastrointestinal tract [1]. Among gastrointestinal duplications, rectal duplication cysts form a small subgroup and account for approximately $4 \%$ of all intestinal duplications [2]. Most of the rectal duplications are located in the retrorectal or posterior rectal region [3] [4]. Anterior (prerectal) location of rectal duplication cyst is extremely rare. Thus, rarity justifies reporting of anterior rectal duplication cyst with emphasis on imaging appearance.

\section{Presentation of Case}

A 9-month-old male was presented with history of acute urinary retention. The general physical and abdominal

${ }^{*}$ Corresponding author.

How to cite this paper: Taori, K., Gour, P.P., Patwa, D., Rathod, J., Disawal, A., Hatgaonkar, A., Bakade, A., Kasat, A. and Kamble, C. (2015) Anterior Rectal Duplication Cyst: A Rare Case Report. Open Access Library Journal, 2: e1418.

http://dx.doi.org/10.4236/oalib.1101418 
examination revealed no abnormality. Digital rectal examination revealed soft mass anterior to rectum. Neurological examination was normal.

Plain radiograph of abdomen revealed no significant bony or soft tissue abnormality.

USG examination (Figure 1) revealed large thin walled cystic mass in prerectal space with fine internal echoes within (possibly due to secondary infection). No obvious communication with rectum was noted. On Color Doppler no vascularity was noted.

Contrast enhanced CT scan (Figure 2) revealed large well defined peripherally enhancing thin walled cystic lesion (Approximate size $4.2 \times 4.9 \times 5.7 \mathrm{cms}$ ) in pelvis anterior to rectum with average attenuation of cyst content $14 \mathrm{HU}$. No calcification/enhancing septations were noted. No associated vertebral anomalies were present.

MRI examination (Figure 3) revealed lesion to be hypointense on T1W and hyperintense on T2W images. It was displacing urinary bladder superiorly. Communication with rectum could not be demonstrated. On DWI (diffusion weighted imaging) no restricted diffusion was noted.

Considering cystic nature and unusual location diagnosis of anterior rectal duplication cystwas primarily kept with mullerian duct cyst as alternative differential.

Surgical excision was planned through posterior sagittal approach (Figure 4) andmass was completely ex-

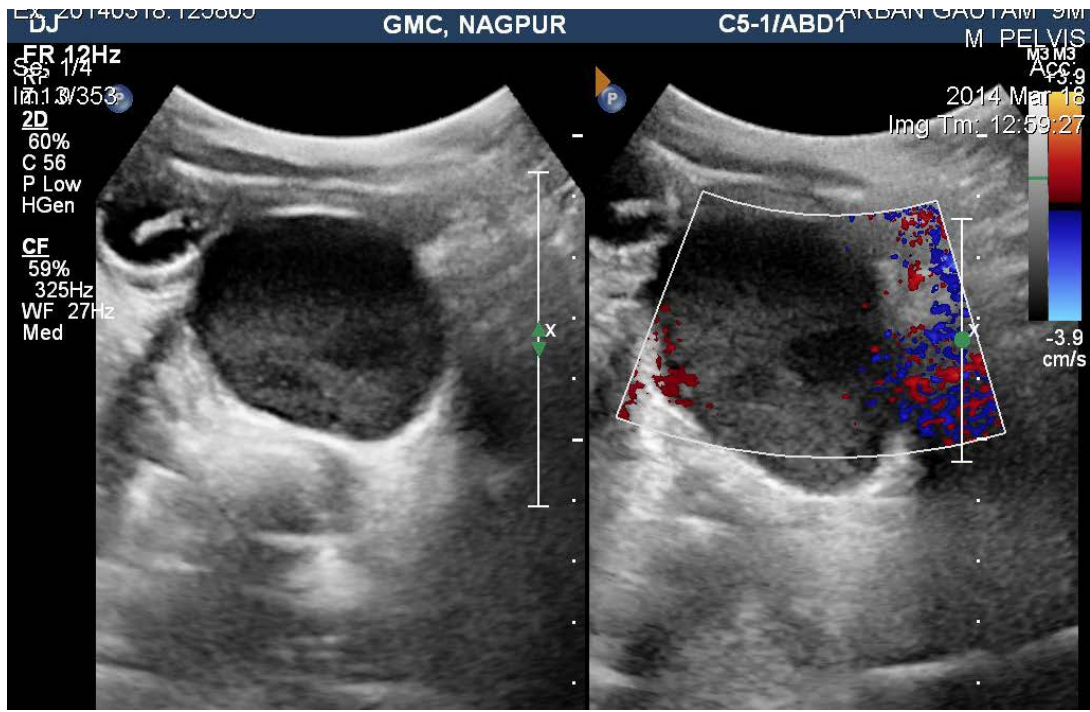

Figure 1. USG and color Doppler images reveals thin walled a vascular cystic lesion in prerectal space with internal echoes.

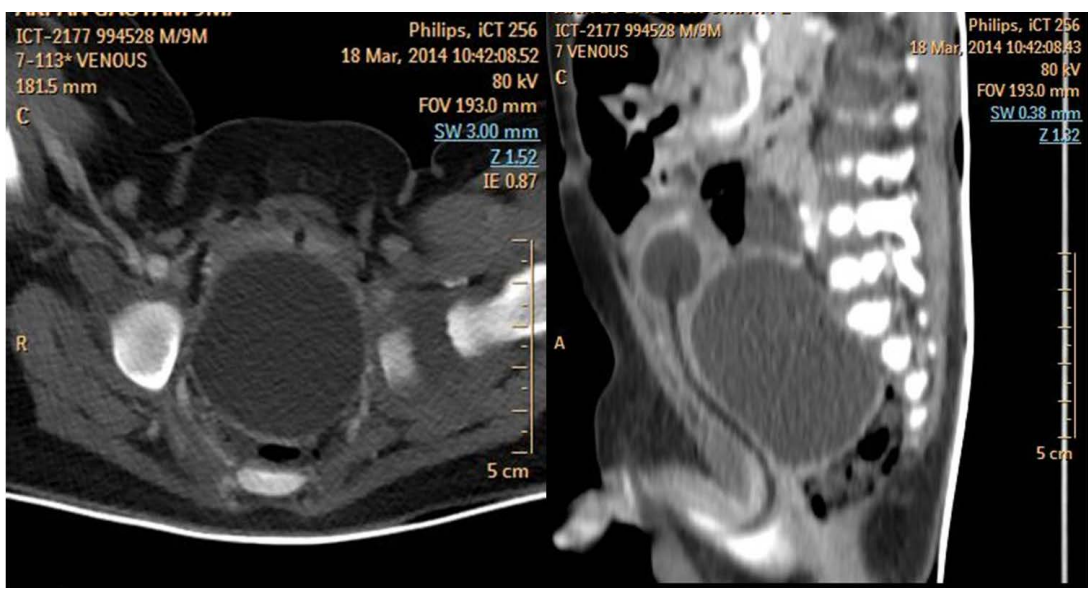

Figure 2. Contrast enhanced CT axial and sagittal images show large peripherally enhancing cystic structure anterior in relation to rectum and displacing bladder superiorly. 


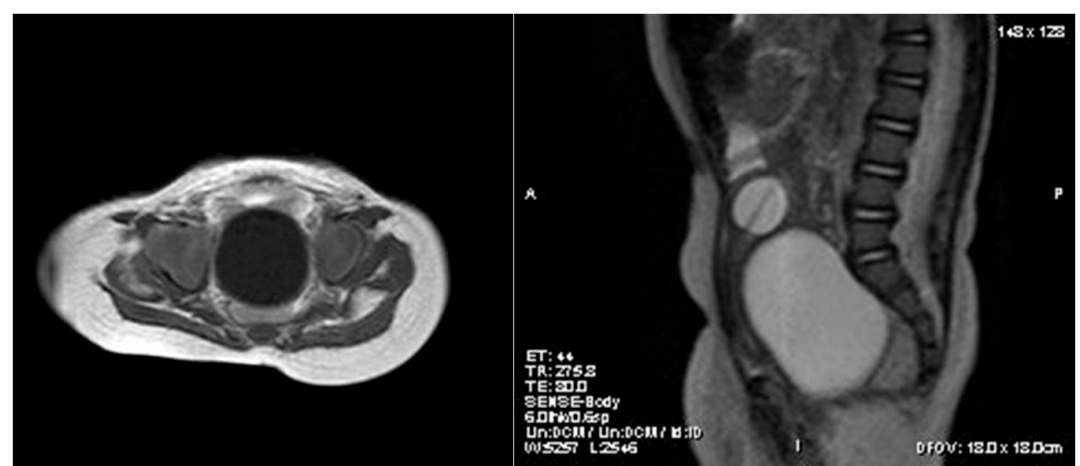

Figure 3. MRI T1W axial and T2W sagittal images reveal cystic mass showing T1 hypo intensity and T2 hyperintensity. Foley's bulb is visualized in urinary bladder.

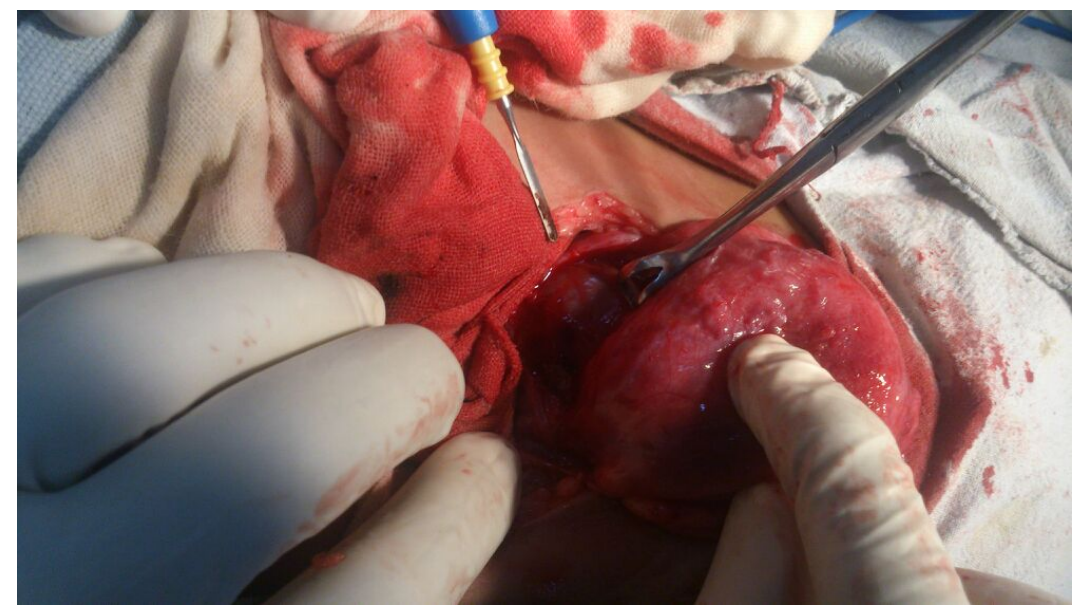

Figure 4. Intra-operative images shows well defined rounded lesion anterior to rectum.

cised after aspiration of turbid fluid. Histopathology of resected mass (Figure 5) showed presence of columnar epithelial lining with well developed muscular coat, thereby confirming the diagnosis of rectal duplications. The postoperative period was uneventful with preserved anorectal functions.

\section{Discussion}

Rectal duplication cysts are rare congenital malformations which usually present in childhood with symptoms of infection, fistulization, rectal bleeding or mass effect such as tenesmus, constipation, prolapse and urinary retention [5]. They are generally cystic and mostly located posteriorly or laterally to rectum. Anterior (prerectal) location is extremely uncommon [3].

Imaging modalities such as USG, CT, MRI, Barium enema helps in characterization of lesions. Ultrasonography reveals cystic nature of lesion. Lesions may demonstrate hyperechoic mucosal surface with surrounding hypoechoic submucosa (Gut signature sign). Internal echoes suggest secondary infection or bleed within lesion. CT, MRI additionally may reveal communication with rectum. Presence of associated genitourinary (double urethra, double bladder), vertebral (spina bifida, meningomyelocoele) and cardiovascular anomalies [6] demands a thorough investigations by MRI and CT.

Differential diagnosis of prerectal midline cystic lesion in male child are anterior rectal duplication cyst, mullerian duct cyst (no communication with urethra and rectum), enlarged prostatic utricle cyst (communication with urethra), epidermoid etc., which provide a diagnostic challenge and hence need a preoperative imaging to narrow the differentials and to come to a specific diagnosis.

Treatment of rectal duplications is primarily surgical and aims at total excision of cyst by posterior sagittal, transanal or transcoccygeal (Kraske) approach with preservation of anal sphincters [5] [7]. 


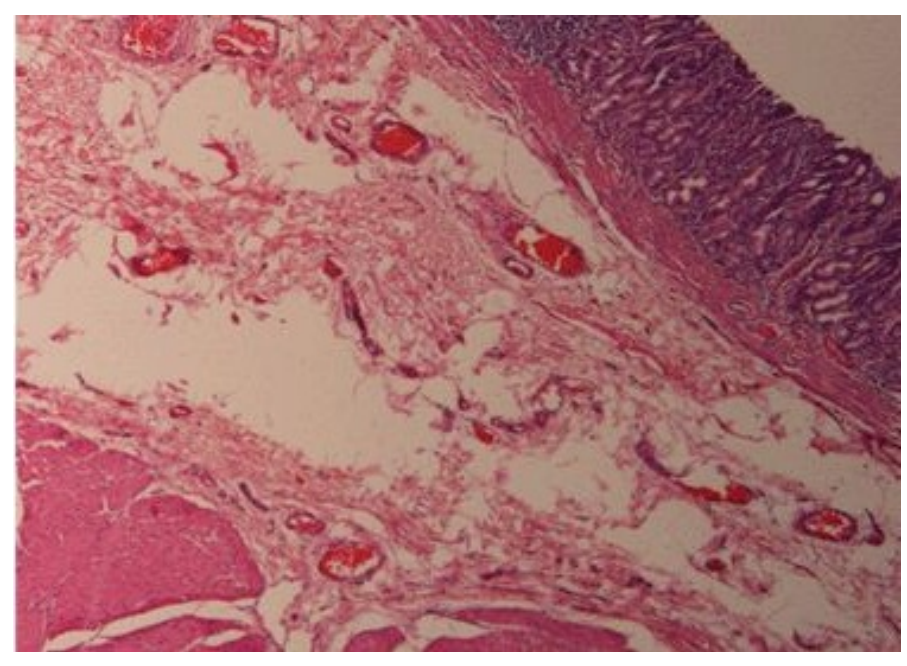

Figure 5. Histopathology-reveals intestinal duplication cyst (columnar epithelial lining with developed muscular coat).

\section{Conclusion}

Thus, we conclude that although occurrence of anterior rectal duplication is extremely rare a thorough radiological evaluation should be done with an aim to diagnose its presence and other associated anomalies at its earliest. Early surgical intervention can be done to avoid undue morbidity associated with above condition.

\section{References}

[1] Ladd, W.E. and Gross, R.E. (1937) Duplications of the Alimentary Tract. Southern Medical Journal, 30, 363-371. http://dx.doi.org/10.1097/00007611-193704000-00002

[2] Park, W.H., Choi, S.O. and Park, K.K. (2001) Cystic Rectal Duplication: A Rare Cause of Neonatal Bladder-Outlet Obstruction and Hydronephrosis. Pediatric Surgery International, 17, 221-223. http://dx.doi.org/10.1007/s003830000461

[3] Knudtson, J., Jackson, R. and Grewal, H. (2003) Rectal Duplication. Journal of Pediatric Surgery, 38, 1119-1120. http://dx.doi.org/10.1016/S0022-3468(03)00248-3

[4] Kızılcan, F., Tanyel, F.C., Kale, G. and Hiçsönmez, A. (1992) Duplication of the Rectum Resembling a Juvenile Polyp. The Turkish Journal of Pediatrics, 34, 193-195.

[5] La Quaglia, M.P., Feins, N., Eraklis, A. and Hendren, W.H. (1990) Rectal Duplications. Journal of Pediatric Surgery, 25, 980-984.

[6] Lister, J. and Rickham, P.P. (1978) Duplications of the Alimentary Tract. In: Rickham, P.P., Lister, J. and Iwing, I.M., Eds., Neonatal Surgery, 2nd Edition, Butterworth, London, 401-410.

[7] Amjadi, K., Poenaru, D., Soboleski, D., Hurlbut, D. and Kamal, I. (2000) Anterior Rectal Duplication: A Diagnostic Challenge. Journal of Pediatric Surgery, 35, 613-614. http://dx.doi.org/10.1016/S0022-3468(03)00248-3 